\title{
Participação Institucionalizada no Contexto Brasileiro: uma Análise do Programa Criança Feliz
}

\section{Institutionalized participation in the Brazilian context: an analysis of the Happy Child program}

Ítalo Henrique de Cristo Almeida

Escola de Governo Professor Paulo Neves de Carvalho - Fundação João Pinheiro - MG E-mail: italo.hem@gmail.com

Resumo: A participação social é um mecanismo imprescindível no que tange a formulação de políticas públicas efetivas e que atinjam de forma relevante as camadas mais vulneráveis da população. No Brasil, tal objeto de estudo ganha força com a promulgação da constituição de 1988, através da institucionalização da participação e do fortalecimento de estruturas como conselhos e fóruns. Nessa alçada, a presente nota de pesquisa tem por objetivo demonstrar como os instrumentos de participação social são importantes para a garantia do interesse público, principalmente em momentos políticos conturbados e de desconfiança. Para tal, realizou-se uma análise de caso sobre o programa federal de cunho assistencialista denominado "Criança Feliz", cujo escopo repercutiu de forma negativa em instâncias participativas federadas e suscitou debates e ações encima de sua implementação.

Palavras-Chave: participação social; conselhos; constituição; democratização; institucionalizada.

\begin{abstract}
Social participation is an indispensable mechanism that hardly becomes one of the most important rules of the population. In Brazil, it promulgated the constitution of 1988, through the institutionalization of participation and strengthening of policies such as councils, forums and unions. In this context, this article aims to demonstrate such as the instruments of institutionalized participation are important for ensuring the public interest and the rights of citizens especially in times of political turmoil and distrust. To this end, a case study was carried out on the federal assistance program called "Happy Child", with the objective of having negative repercussions in federated participatory instances and has aroused discussions and actions on its implementation.
\end{abstract}

Keywords: social participation; advices; constitution; democratization; institutionalized. 
ALMEIDA, Ítalo Henrique de Cristo. Participação Institucionalizada no Contexto Brasileiro: uma Análise do Programa Criança Feliz.

\section{Introdução}

A formulação da agenda de políticas públicas, ou agenda governamental, definida pelo teórico John Kingdom (2001) como o conjunto de assuntos que vão ser abarcados pela ação do poder público em um determinado intervalo de tempo, é um processo que envolve diversos agentes, os quais influenciam diretamente na tomada de decisão. Dentre esses, nas últimas décadas do cenário brasileiro, ganham cada vez mais relevância os movimentos de participação social, cuja intervenção é imprescindível para a implementação de projetos que incidam de forma direta nos problemas das camadas mais vulneráveis da sociedade.

Segundo Abers (2016) a participação da sociedade civil em decisões sobre projetos de desenvolvimento não é uma proposta nova, de forma que, desde o final dos anos 1970, agências multilaterais, especialmente das Nações Unidas, recomendam sistematicamente o uso de técnicas participativas na realização de projetos de desenvolvimento. No Brasil, a ascensão da participação social na democracia brasileira emerge, como é colocado por Leonardo Avritzer (2016), durante a origem da democratização (1985 -1988). Nesse período há a ocorrência de diversos fenômenos que corroboram para esse processo, e dentre eles destaca-se aqui o desenvolvimento da participação institucionalizada, que emergiu com a promulgação da Constituição de 1988 e com as legislações infraconstitucionais que lhe seguiram (Avritzer, 2016). A Carta constitucional agregou uma versão mais ampla do exercício da democracia, que se daria não apenas de forma representativa e indireta, mas também participativa e direta. Foram instituídas diversas instâncias de participação direta, como conselhos, conferências, audiências públicas, orçamentos participativos, entre outros, que buscavam ampliar os atores envolvidos no processo decisório. (Cavalcante et al. 2018)

As literaturas que defendem essa institucionalidade acreditam que esse instrumento é benéfico não só para os cidadãos, como também para o próprio Estado, uma vez que proporciona o aumento da eficácia das ações governamentais. Nesse sentido, a participação institucionalizada ganha força não somente como mecanismo de auxílio na implementação de políticas sócias, mas também como barreira para a retirada de direitos e benefícios conquistados pela sociedade, principalmente em momentos de crise política e econômica.

Revista Brasileira de Políticas Públicas e Internacionais, v.4, n.1, julho/2019, pp. 220-229. 
ALMEIDA, Ítalo Henrique de Cristo. Participação Institucionalizada no Contexto Brasileiro: uma Análise do Programa Criança Feliz.

Pretende-se então demonstrar como os instrumentos participativos impedem essa regressão dos direitos adquiridos pela sociedade, principalmente no que tange às parcelas mais vulneráveis da população. Para tal, será analisado o caso do programa Criança Feliz, programa elaborado no governo de Michel Temer com o objetivo de auxiliar a primeira infância das crianças de baixa renda, e a partir de aí identificar como os instrumentos de participação institucionalizada contribuíram para a defesa dos direitos da sociedade.

\section{Participação Social no Brasil}

A ideia de participação social pode ser entendida como uma forma de os cidadãos conseguirem se organizar e induzir certa influência sobre o processo decisório das políticas públicas de sua região. Dessa forma, tem-se a participação social como mecanismo imprescindível para a promoção da democracia, dotando a sociedade de poder decisório que vai além do voto.

Segundo Avritzer (2016) a democracia brasileira é identificada no mundo inteiro pela marcante presença de movimentos e de atores sociais. Entretanto ao analisar a história do país, pode-se observar uma marcante hegemonia de uma elite governante, a qual não permitia a participação do povo, de forma a forçá-lo a aceitar aquilo que era proposto. Tal fato histórico pode ser considerado como uma herança colonial, que partiu de uma monarquia absolutista e escravocrata, a qual utilizava do país como colônia de exploração, perpetuando assim a cultura da imposição e da centralização do poder. O cenário torna-se ainda mais desfavorável com a intervenção militar, que não contempla qualquer estratégia de participação popular, conduzindo o país de forma cada vez mais centralizada e repressiva.

Nesse sentido, é importante ressaltar que, apesar da constante repressão à participação social nos momentos decisórios, o povo brasileiro conservou sua essência participativa, o que foi imprescindível para a derrocada rumo redemocratização. Em meados dos anos 70, movimentos populares reivindicando maior participação tiveram papel imprescindível para o enfraquecimento e posterior queda do regime militar.

Assim, após mais de duas décadas de regime ditatorial, as deliberações da Assembleia Constituinte de 1986 que culminaram na promulgação da Constituição Federal de 1988

Revista Brasileira de Políticas Públicas e Internacionais, v.4, n.1, julho/2019, pp. 220-229. 
ALMEIDA, Ítalo Henrique de Cristo. Participação Institucionalizada no Contexto Brasileiro: uma Análise do Programa Criança Feliz.

estabeleceram as bases jurídicas de um Estado democrático (Cavalcante et al. 2018). Nesse período, como apontado por Avritzer (2016) ocorreram fenômenos históricos importantes que corroboraram para o fortalecimento do processo de participação, como a derrota histórica da direita brasileira, que culminou posteriormente no rompimento da interdição ao processo participativo e encadeia perspectivas de mobilização social como o das diretas já em 1984 e o processo da participação institucionalizada, que foi o elemento do projeto participativo que mais se desenvolveu no país, emergindo com a promulgação da constituição de 1988 e as legislações que a seguem.

A década de 90 apresenta-se então como o momento de maior expansão da participação social no país, no nível local, nas áreas de saúde e políticas urbanas que desencadearam formas intensas de participação (Avritzer, 2016). Nesse período tem-se a inauguração do orçamento participativo por Olívio Dutra, então presidente de Porto Alegre, modelo que se espalha por centenas de municípios. Com o passar dos anos, novos métodos de participação institucionalizadas vão sendo incorporados no contexto brasileiro, como as conferências nacionais em 2003, os conselhos, fóruns regionais, dentre outros, de maneira a não só promover o processo de democratização no país, como a dar voz aos níveis regionais dos entes federativos e à população, de maneira que a formulação das políticas públicas se aproxima cada vez mais da realidade dos beneficiários.

Nesse sentido, destacam-se aqui o Conselho Nacional de Saúde (CNS) e o Conselho Nacional de Assistência Social (CNAS), que se constituem de instâncias colegiadas deliberativas, referentes respectivamente ao Sistema Único de Saúde (SUS) e ao Sistema Único de Assistência Social (SUAS). Esses instrumentos de participação institucionalizada, assim como outros advindos e fortalecidos pela constituição de 1988, são de suma importância para o direcionamento eficiente de políticas públicas referentes à suas áreas de atuação, uma vez que, através dos mesmos, é possível entender a situação das áreas mais vulneráveis e dos seus beneficiários, tendo em vista a aproximação proporcionada pelas conferências e pelas reuniões com os representantes civis.

Dessa forma, esses mecanismos proporcionam à população não só a possibilidade de participar na deliberação e formação das políticas públicas de saúde e assistência social, como

Revista Brasileira de Políticas Públicas e Internacionais, v.4, n.1, julho/2019, pp. 220-229. 
ALMEIDA, Ítalo Henrique de Cristo. Participação Institucionalizada no Contexto Brasileiro: uma Análise do Programa Criança Feliz.

também visam a proteção de seus direitos e a garantia de que os recursos estão sendo direcionados da forma mais eficiente e mais assertiva possível. Tal premissa pode ser observada com a análise do caso do Programa Criança Feliz, criado pelo governo de Michel Temer em 2016 com a proposta de promover o desenvolvimento de crianças de 0 a 3 anos beneficiárias do Bolsa Família e as de até 6 anos que recebem Benefício de prestação Continuada, e que suscitou intensa discussão acerca de sua efetividade e por oferecer o serviço por meio de agentes que não fazem parte dos serviços oferecidos pela Assistência Social, descumprindo a política do SUAS.

\section{Programa Criança Feliz}

O programa “Criança Feliz” é uma iniciativa lançada em 2016 pelo Governo Federal, tendo como embaixadora a ex primeira dama Marcela Temer, instituído pelo Decreto $\mathrm{N}^{\circ} 8.869$ de 2016, com o intuito de ampliar a rede de atenção e cuidado integral das crianças na primeira infância, que nos termos da Lei $\mathrm{N}^{\circ}$ 13.257/2016 é considerada como o período que abrange os seis primeiros anos da vida da criança. Nesse período, a relação da criança com o mundo que a cerca é proveniente da mediação familiar, cuja importância é relacionada diretamente ao seu desenvolvimento.

O método utilizado para o atendimento das famílias consiste no chamado Care for Child Development (CCD), do Fundo das Nações Unidas para Infância (Unicef), cujo desenvolvimento foi realizado pela professora Jane Lucas da Universidade de Nova Iorque.

Assim, programa é desenvolvido através de visitas domiciliares, cuja finalidade é promover o desenvolvimento integral das crianças na primeira infância, buscando envolver ações intersetoriais de saúde, educação, assistência social, cultura e direitos humanos. O alvo do programa consiste em gestantes e pais de crianças com até 3 anos e de baixa renda que são beneficiários do Bolsa Família. Além disso, são também atendidas crianças de até 6 anos portadoras de deficiência que sejam incluídas no Benefício de Prestação Continuada.

Dentre os objetivos do programa, presentes no Art. $3^{\circ}$ do Decreto 8.868/2016, podem ser destacados o apoio à gestante e as famílias na preparação para o nascimentos e cuidados perinatais, fortalecer os vínculos parentais e o papel da família no desenvolvimento da criança,

Revista Brasileira de Políticas Públicas e Internacionais, v.4, n.1, julho/2019, pp. 220-229. 
ALMEIDA, Ítalo Henrique de Cristo. Participação Institucionalizada no Contexto Brasileiro: uma Análise do Programa Criança Feliz.

mediar o acesso das famílias aos serviços públicos e integrar e fortalecer ações de políticas públicas voltadas para as famílias durante esse período da primeira infância.

Até dezembro de 2018, os números do programa fornecidos pelo portal do Ministério da Cidadania apontam:

- $\quad 356$ mil crianças atendidas

- 65 mil gestantes atendidas

- 2678 Municípios participantes

- 2400 Municípios já realizaram visitas domiciliares

- $\quad 13,6$ mil visitadores

- $\quad 2,5$ mil Supervisores

\section{O Programa Criança Feliz e a Influência dos Conselhos}

Um dos modelos de participação institucionalizada no Brasil que possui grande influência sobre as decisões dos formadores de políticas públicas consiste nos conselhos. Tal mecanismo constitui-se de espaços públicos de composição plural e paritária entre Estado e sociedade civil, de natureza deliberativa e consultiva, cuja função é formular e controlar a execução das políticas públicas setoriais (Secretaria de Relações institucionais e Temáticas, Itajaí, SC, 2019). Dessa forma, os conselhos podem ser tidos como um dos principais canais de participação popular, sendo encontrado nas três instâncias federativas.

Nesse sentido, é imprescindível o papel do Conselho Federal de Serviço Social CFESS, que constitui em uma autarquia pública federal, tendo como atribuição orientar, disciplinar, normatizar, fiscalizar e defender o exercício profissional do/a assistente social no Brasil, em conjunto com os Conselhos Regionais de Serviço Social - CRESS (CFESS, 2019).

No dia 07 de março de 2017, o CFESS divulgou, durante reunião da Comissão de Políticas Públicas do Conselho Nacional de Assistência Social uma nota pública intitulada "Porque dizer não ao programa Criança Feliz". Segundo o documento, o conselho manifestou seu posicionamento contrário tanto na concepção do programa quanto na forma que o governo federal utilizou para a adesão dos demais entes federados e sua operacionalização, alegando desrespeito às instâncias de controle social. Dentre as críticas apresentadas estão o retorno do

Revista Brasileira de Políticas Públicas e Internacionais, v.4, n.1, julho/2019, pp. 220-229. 
ALMEIDA, Ítalo Henrique de Cristo. Participação Institucionalizada no Contexto Brasileiro: uma Análise do Programa Criança Feliz.

"primeiro damismo" na Política Assistencial, a falta de diálogo do governo federal com a sociedade, a priorização do terceiro setor e a desresponsabilização do Estado pela oferta de serviços públicos de saúde e educação com qualidade desde a primeira infância.

Além do CFESS, outros modelos de participação institucionalizada manifestaram-se contrários ao programa, como sindicatos relacionados à assistência social, como o Sindicato dos Trabalhadores da Assistência Social e Cultura - SINDSASC, além de conferências e fóruns regionais que trouxeram a época o assunto como pauta em suas discussões.

Atualmente o programa continua ativo, apesar de toda repercussão negativa e das manifestações contrárias de movimentos sociais, mas com corte significativo de $50 \%$ das vagas planejadas, conforme demonstrado em matéria do jornal digital NEXO (2017), referente a resistência dos conselhos, de forma que embates movidos por eles e outros entes participativos, foram e continuam sendo de suma importância nos âmbitos não só de transmissão de seus posicionamentos junto a comunidade, como também de exteriorização e fortalecimento das cobranças frente ao próprio governo, assegurando a busca pelo interesse da sociedade, em especial das camadas mais vulneráveis que dependem de programas sociais como forma de ascensão e sobrevivência.

Assim, é importante ressaltar a dualidade dos resultados obtidos pela atuação dos instrumentos de participação institucionalizada nesse caso. Em um primeiro momento, os conselhos serviram como veículo de informação e transparência, haja visto que as decisões de formulação e implementação do programa foram realizadas de forma top down.

Em uma segunda abordagem, tais instrumentos foram imprescindíveis em levantar questionamentos e movimentos de resistências a uma política que se desenhava de forma a não englobar de forma eficiente as necessidades dos cidadãos de baixa renda, em detrimento a um modelo de política de primeiro damismo.

Sendo assim, os cortes e modificações realizadas no projeto demonstram como a institucionalização foi importante, principalmente nesse cenário político conturbado em que o país estava imerso durante o desenvolvimento do programa.

Revista Brasileira de Políticas Públicas e Internacionais, v.4, n.1, julho/2019, pp. 220-229. 
ALMEIDA, Ítalo Henrique de Cristo. Participação Institucionalizada no Contexto Brasileiro: uma Análise do Programa Criança Feliz.

\section{Considerações Finais}

A participação social é uma característica presente na sociedade brasileira, sendo reprimida durante muito tempo pelas elites governantes, mas que encontrou na promulgação da carta magna de 88 o espaço que demandava para exercer a influência do povo sobre as tomadas de decisão.

Entretanto, a participação e a opinião popular ainda enfrentam barreiras para exercerem seu papel de forma íntegra, principalmente em vias da herança totalitária que a estrutura governamental brasileira ainda preserva. Nesse sentido, pode-se citar a obra de Tatagiba e Teixeira (2006) que demonstram através da análise do caso do orçamento participativo da prefeitura de São Paulo no período de 2001 a 2004 a importância da autonomia das instituições participativas, visto que, ao tratar dessa autonomia desses instrumentos significa perguntar sobre a natureza dos vínculos que os movimentos são capazes de estabelecer com os demais atores do sistema político, significa perguntar até que ponto eles são capazes, nessa relação, de escolher os seus interlocutores em função das suas agendas, de defender seus interesses, de definir os objetivos da interação, e até que ponto eles pautam ou são pautados. (Tatagiba e Teixeira 2006)

Assim, o caso analisado do programa Criança Feliz é um grande exemplo dessa realidade, uma vez que, a formulação e a tomada de decisão dos formuladores de políticas públicas e dos políticos foram concretizadas sem a participação e opinião popular, cabendo aos instrumentos como os conselhos e os sindicatos agirem em prol dos interesses sociais e da defesa dos direitos adquiridos.

Logo, é imprescindível a atuação da participação institucionalizada, inclusive em um contexto político como o do Brasil, em que nem sempre as decisões parecem ser tomadas em vista da justiça social. Como pode ser observado, o CFESS foi e ainda é de suma importância na garantia da manutenção e cumprimento dos direitos sociais de assistência social, e as manifestações e cobranças realizadas sobre o programa Criança Feliz corroboram para a afirmação dessa premissa, fazendo com que o haja o constante embate em prol do interesse social.

Revista Brasileira de Políticas Públicas e Internacionais, v.4, n.1, julho/2019, pp. 220-229. 
ALMEIDA, Ítalo Henrique de Cristo. Participação Institucionalizada no Contexto Brasileiro: uma Análise do Programa Criança Feliz.

Sendo assim, realizando uma perspectiva de longo prazo, é importante salientar como esses instrumentos de participação serão determinantes no tocante à garantia da formulação de políticas públicas eficientes e que atinjam de forma significativa aqueles com menor vulnerabilidade, uma vez que esses, por muitas vezes, não detêm a mesma possibilidade de expressar suas necessidades e opiniões acerca de determinada política que os grandes stakeholders possuem. Dessa forma, é importante não só ter os mecanismos de participação institucionalizada, mas garantir que a população tenha acesso a estes e que sua participação desemboque em resultados significativos, ou seja, não sejam apenas "elefantes brancos" que manipulam e instrumentalizam os espaços participativos, elaborados para servir como meio de legitimação de políticas sem dar a devida importância a opinião dos principais agentes envolvidos, que são as comunidades afetadas pelos programas.

\section{Referências}

ABERS, Rebecca Neaera. (2016). Conflitos, Mobilizações e Participação institucionalizada: A relação entre a sociedade civil e a construção de grandes obras de infraestrutura. IPEA.

Recuperado em 07 de maio de 2019, de http://www.ipea.gov.br/portal/ index.php?option=com_content\&view=article\&id=28679:td-2231-conflitos-mobilizacoes-eparticipacao-institucionalizada-a-relacao-entre-a-sociedade-civil-e-a-construcao-de-grandesobras-de-infraestrutura\&catid=390:2016\&directory=1

AVRITZER, Leonardo. (2016). Impasses da Democracia no Brasil. Rio de Janeiro: Editora Civilização Brasileira.

CAVALCANTE, Pedro. LOTA, Gabriela S. OLIVEIRA, Vanessa Elias de. (2018). Do insulamento burocrático à governança democrática: as transformações institucionais e a burocracia no Brasil. IPEA. Recuperado em 05 de maio de 2019, de http://repositorio.ipea.gov.br/bitstream/11058/8561/1/Do\%20Insulamento.pdf

CUNHA, Eleonora Schettini Martins. (2004). Participação política e o enfrentamento da questão social: o potencial dos conselhos de políticas e do orçamento participativo no Brasil. VIII Congresso Luso-Afro-Brasileiro de Ciências Socais - A Questão Social no Novo Milénio Recuperado em 21 de julho de 2019, de https://www.ces.uc.pt/lab2004/pdfs/Eleonora Cunha.pdf

KINGDON, John W. (2001). A model of agenda-setting, with applications. Law Review, Michigan State University - Detroit College of Law (MSU-DCL), 2 (331). p. 331 - 337,

Revista Brasileira de Políticas Públicas e Internacionais, v.4, n.1, julho/2019, pp. 220-229. 
ALMEIDA, Ítalo Henrique de Cristo. Participação Institucionalizada no Contexto Brasileiro: uma Análise do Programa Criança Feliz.

Recuperado em 21 de julho de 2019, de http://readinglists.ucl.ac.uk/items/ 52F0373B-2739-9014-0A7B-52E5AFBAB206.html

TATAGIBA, Luciana. TEIXEIRA, Ana Cláudia Chaves. (2006). Participação e Democracia: Velhos e novos desafios. Civitas - Revista de ciências Sociais. Recuperado em 15 de maio de 2019, de http://revistaseletronicas.pucrs.br/ojs/index.php/civitas/article/view/30/1594

SOUZA, Nivaldo. (2017). Quais os problemas do programa "Criança Feliz", comandado pela primeira-dama. Nexo Jornal. Recuperado em 20 de abril de 2019, de

https://www.nexojornal.com.br/expresso/2017/05/21/Quais-os-problemas-do-programa-\%E2\%80\%98 Crian\%C3\%A7a-Feliz\%E2\%80\%99-comandado-pela-primeira-dama

Conselho Federal de Serviço Social (CFESS). Informações Gerais: O CFESS. Disponível em <http://www.cfess.org.br/visualizar/menu/local/o-cfess>. Acesso em 13 de maio de 2019.

Secretaria de Relações institucionais e Temáticas. O que são e para que servem os Conselhos Municipais. Recuperado em 15 de maio de 2019, de https://serit.itajai.sc.gov.br/c/o-que-sao-epara-que-servem-os-conselhos-municipais

Revista Brasileira de Políticas Públicas e Internacionais, v.4, n.1, julho/2019, pp. 220-229. 